\title{
The Alto Tiberina Near Fault Observatory (northern Apennines, Italy)
}

\author{
Lauro Chiaraluce ${ }^{1, \star}$ Alessandro Amato ${ }^{1}$, Simona Carannante ${ }^{1}$, Viviana Castelli ${ }^{1}$, \\ Marco Cattaneo ${ }^{1}$, Massimo Cocco $^{1}$, Cristiano Collettini ${ }^{2}$, Ezio D’Alema ${ }^{1}$, \\ Raffaele Di Stefano ${ }^{1}$, Diana Latorre ${ }^{1}$, Simone Marzorati ${ }^{1}$, Francesco Mirabella ${ }^{3}$, \\ Giancarlo Monachesi ${ }^{1}$, Davide Piccinini ${ }^{1}$, Adriano Nardi $^{1}$, Antonio Piersanti ${ }^{1}$, \\ Salvatore Stramondo ${ }^{1}$, Luisa Valoroso ${ }^{1}$
}

\author{
${ }^{1}$ Istituto Nazionale di Geofisica e Vulcanologia, Italy \\ ${ }^{2}$ La Sapienza - Università di Roma, Dipartimento di Scienze della Terra, Rome, Italy \\ ${ }^{3}$ Università di Perugia, Dipartimento di Scienze della Terra, Perugia, Italy
}

\author{
Article history \\ Received October 16, 2013; accepted May 7, 2014. \\ Subject classification: \\ Earthquake source and dynamics, Tectonics, Earthquake faults, Near fault observatory, Low angle normal faults.
}

\begin{abstract}
The availability of multidisciplinary and high-resolution data is a fundamental requirement to understand the physics of earthquakes and faulting. We present the Alto Tiberina Near Fault Observatory (TABOO), a research infrastructure devoted to studying preparatory processes, slow and fast deformation along a fault system located in the upper Tiber Valley (northern Apennines), dominated by a $60 \mathrm{~km}$ long low-angle normal fault (Alto Tiberina, ATF) active since the Quaternary. TABOO consists of 50 permanent seismic stations covering an area of $120 \times 120 \mathrm{~km}^{2}$. The surface seismic stations are equipped with 3-components seismometers, one third of them hosting accelerometers. We instrumented three shallow $(250 \mathrm{~m})$ boreholes with seismometers, creating a 3-dimensional antenna for studying micro-earthquakes sources (detection threshold is $M_{L} 0.5$ ) and detecting transient signals. 24 of these sites are equipped with continuous geodetic GPS, forming two transects across the fault system. Geochemical and electromagnetic stations have been also deployed in the study area. In 36 months TABOO recorded 19,422 events with $M_{L} \leq 3.8$ corresponding to 23.36e-04 events per day per squared kilometres; one of the highest seismicity rate value observed in Italy. Seismicity distribution images the geometry of the ATF and its antithetic/synthetic structures located in the hanging-wall. TABOO can allow us to understand the seismogenic potential of the ATF and therefore contribute to the seismic hazard assessment of the area. The collected information on the geometry and deformation style of the fault will be used to elaborate ground shaking scenarios adopting diverse slip distributions and rupture directivity models.
\end{abstract}

\section{Introduction: A natural laboratory}

Crustal faults are complex natural systems whose mechanical properties evolve with time. Thus, the understanding of the multi-scale physical-chemical processes responsible for earthquakes and faulting requires considering phenomena at the boundaries between different research fields (road of integration) and the availability of long time series of high-resolution data.

With this aim we have been working for the past five years in the creation of what we called a Near Fault Observatory (NFO), consisting of a multidisciplinary research infrastructure based on state of the art observational systems continuously recording high quality data related to the underlying tectonic processes over a broad time interval. Such methodological approach based on an extremely high spatial resolution can be more easily applied at the local scale.

There are four main requirements for an area to be a suitable candidate as NFO: 1 ) it has to host active faults; 2) it has to be relatively small in terms of spatial scale (determined by the fault dimensions); 3 ) it must be characterised by a relatively high seismicity rate and 4) it has to be instrumented with multidisciplinary monitoring systems.

The area we selected as natural laboratory is located along the upper Tiber Valley within the inner sector of the northern Apennines (inset of Figure 1). According to the interpretation of few hundreds of kilometres of seismic reflection profiles [Pialli et al. 1998, Mirabella et al. 2011], the existence of a $60 \mathrm{~km}$ long extensional fault system active in the Quaternary and dominated at depth by an east-dipping low angle normal fault (dip $15^{\circ}-25^{\circ}$ ), named Alto Tiberina Fault (ATF) [Barchi et al. 1998, Boncio et al. 2000], is documented in this area. The ATF 


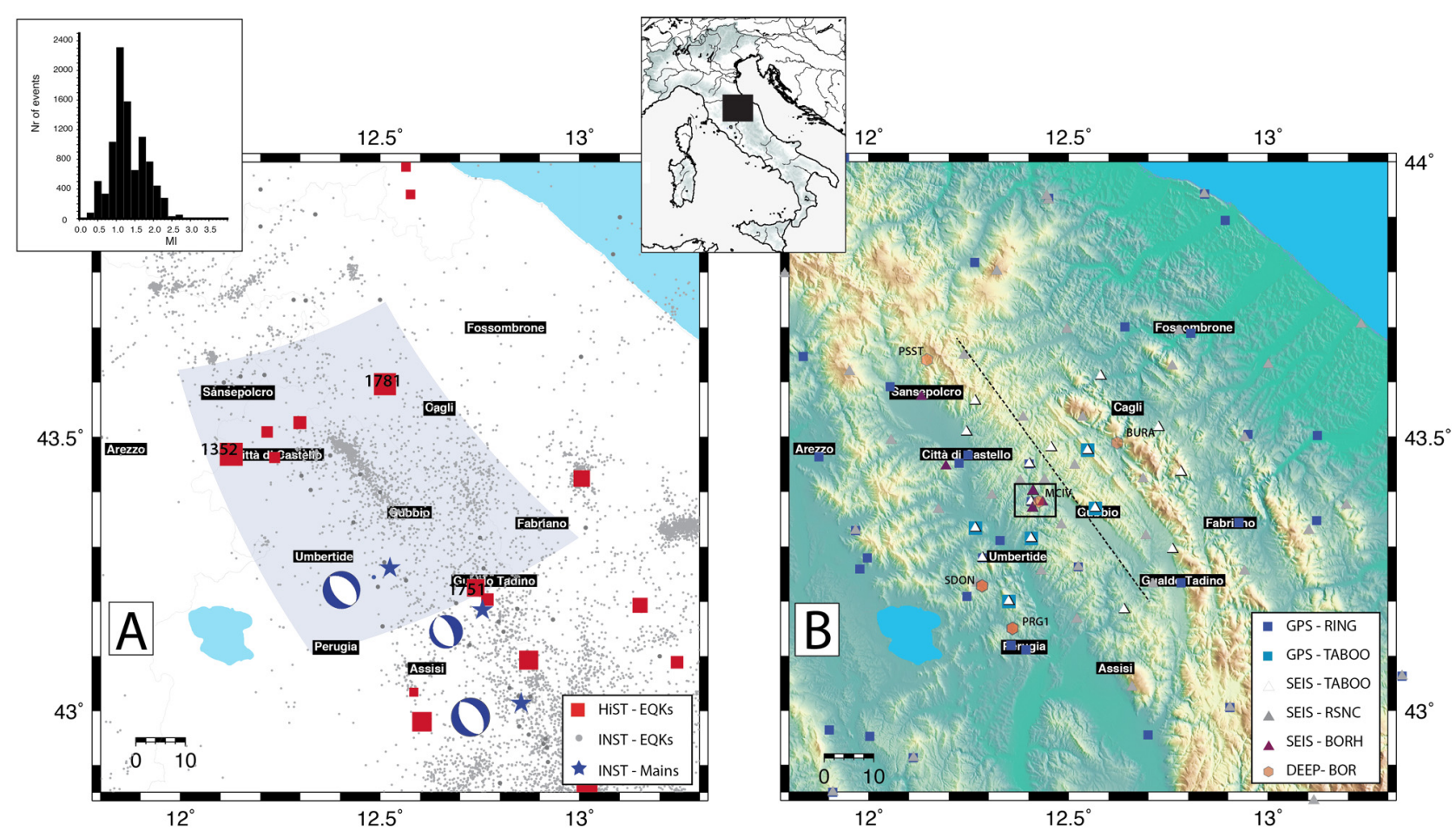

Figure 1. Map of the study area located in the inner sector of the northern Apennines (see inset on the right). (A) Largest historical and instrumental seismicity of the area. The red squares (scaled with magnitude; Rovida et al. [2011]) represent the macro-seismic location of the largest events occurred in the past 1000 years. Grey points represent the epicentral location (from the catalogue of the INGV national network available at: http://iside.rm.ingv.it/iside/standard/index.jsp) of the earthquakes occurred in between 1995-2010. The inset on the left shows the magnitude distribution for this catalogue with completeness around M 1.5. The blue stars and beach balls are the locations of the largest instrumental earthquakes and focal mechanism solutions, respectively. See text for details. The light blue box represents the projection at surface of the Alto Tiberina fault plane (after Mirabella et al. [2011]). (B) Map of the station distribution and location of the already existing deep boreholes. See text for explanation. The shaded line is the cross section trace of Figure 2.

bounds the western flank of the high Tiber Quaternary basin and has accumulated a minimum time-averaged long-term slip rate of about $1-3 \mathrm{~mm} /$ year in the last 2 Myear [Collettini and Holdsworth 2004, Mirabella et al. 2011] without large historical events unambiguously associated with this fault. Whilst, a set of synthetic and antithetic high angle faults that generated moderate events both in historical and instrumental epoch (Figure $1 \mathrm{~A}$ ) are located in the hanging-wall of the ATF. The NFO is devoted to the identification and understanding of the short- versus long-term deformation processes linked to the seismic and/or aseismic activity along this normal fault system. The presence of very high fluids (mostly $\mathrm{CO}_{2}$ ) pressure ( $85 \%$ of the lithostatic load) at 4-5 $\mathrm{km}$ of depth, further motivated the deployment of this observing system.

We have initiated the construction of this research infrastructure in 2009 relying on both INGV (Istituto Nazionale di Geofisica e Vulcanologia) dedicated resources and Italian and European projects funding. In order to optimize the data acquisition, the new deployed monitoring stations have been built complementarily to the existing stations of the INGV national and regional seismic and geodetic networks. The network is now totally up and running [Monachesi e Cat- taneo 2010, D’Alema et al. 2011, Monachesi et al. 2013], covering a $120 \times 120 \mathrm{~km}^{2}$ zone surrounding the ATF system (shaded area in Figure 1A).

In the following we describe the ATF Near Fault Observatory and the researches that we plan to perform with this observing system.

\section{Scientific rationales}

The earthquake recurrence models based on historical seismicity might involve large uncertainties due to sparse or incomplete information on large magnitude earthquakes and their association with a specific fault system, particularly when applied at local scale. In these circumstances, the analysis of micro-seismicity represents a unique tool to investigate the seismicity pattern and identify active tectonic structures. The joint investigation of seismicity and tectonic deformation through geodetic measurements and geological observations represents an effective approach to identify small- and large-scale tectonic processes. This requires the deployment of dense networks of instruments to enhance the detection power and increase the resolution of the observing system. The increased capability to detect signals from active tectonic processes occurring in the crust surrounding the investigated fault sys- 
tem (e.g. earthquakes, creep events, transients, slow deformation) as well as to monitor their spatio-temporal evolution guarantees the progress toward the understanding of the mechanical behaviour of faults. In this framework, the selected study area represents a unique place to investigate the mechanics of a low-angle normal fault making this research infrastructure of global interest for geo-scientists.

Hereinafter we identify the area monitored by The Alto Tiberina Near Fault Observatory (TABOO; http:/ / taboo.rm.ingv.it/) as the projection at the surface of the ATF plane reconstructed by the use of seismic reflection profiles and surface geology (Mirabella et al. [2011]; shaded area in Figure 1A).

The ATF is in fact documented in large sets of data including surface and subsurface geology and geophysical data [Barchi et al. 1998, Boncio et al. 2000, Collettini and Barchi 2002, Chiaraluce et al. 2007, Brozzetti et al. 2009, Mirabella et al. 2011]. A series of seismic reflection profiles have been acquired (CROP03 project; Pialli et al. [1998] and commercial profiles Collettini et al. [2000], Mirabella et al. [2011]), to image the structures characterising the lower and upper crust. In addition, a series of deep boreholes ranging 0-6 km of depth, have been drilled around 1980's for oil exploration purposes (Figure 1B, Anelli et al. [1994]), providing additional information on the already well-known stratigraphic succession and elastic properties of the rocks [e.g. Trippetta et al. 2010]. Furthermore, the seismic reflection profiles calibrated by deep boreholes information have been used to reconstruct at high resolution (kilometre scale), the geometry of the faults at depth including the ATF [Mirabella et al. 2011, and reference therein].

The ATF is a $\approx 60 \mathrm{~km}$ long NNW-trending normal fault dipping $15^{\circ}$ toward ENE. In the hanging-wall block higher angle synthetic and antithetic structures have generated moderate magnitude events, such as the $\mathrm{M}_{\mathrm{W}} 5.11984$ Gubbio earthquake (Figure 1A; Westaway et al. [1989], Collettini e al. [2003]). Up to now only micro-earthquakes $\left(M_{L}<3.0\right)$ have been observed to continuously nucleate along the ATF plane [Chiaraluce et al. 2007, De Luca et al. 2009], at high and constant rate of $r=7.30 \mathrm{e}-04 \mathrm{eqks} /$ day $* \mathrm{~km}^{2}$ [Chiaraluce et al. 2009]. The $10 \%$ of these earthquakes repeatedly rupture the same fault patch and thus, according to the literature [Cole and Ellsworth 1995], can be defined repeaters [Chiaraluce et al. 2007]. The seismicity located along the ATF is kinematically consistent with the local tectonic setting characterized by the ATF low-angle plane and shows a higher $b$-value than the seismicity located in the hanging-wall block (antithetic structures) suggesting different fault zone rheology or frictional properties within this fault system.
It is worth noting that the micro-seismicity nucleating along the ATF is not able to explain the deformation associated with the short- and long-term slip rate inferred by geological [Collettini and Holdsworth 2004] and geodetic studies [D'Agostino et al. 2009], respectively. These observations together with the lack of a large magnitude historical earthquake [Rovida et al. 2011, and reference therein] that in the past 1000 years may have ruptured the whole ATF length (i.e. M 7), suggest the presence of aseismic deformation and creeping fault behaviour, as proposed by Hreinsdóttir and Bennett [2009] investigating regional GPS data. This behaviour would be coherent with the observation that no moderate-to-large magnitude earthquakes have been documented worldwide on low angle normal faults (LANF) using positively discriminated focal mechanisms [Jackson and White 1989, Collettini and Sibson 2001]. This is the reason why LANFs have been considered unimportant structures in terms of seismic hazard. On the contrary Finocchio et al. [2013] by means of a 2D elastoplastic finite-element model reproducing the very large scale interseismic deformation pattern observed by GPS data, propose an ATF completely locked.

The seismogenic potential of LANF is indeed still debated in the literature [Jackson and White 1989, Buck 1993, Westaway 1999, Collettini and Sibson 2001, Collettini 2011]. LANFs are faults characterized by very low dip angles $\left(<30^{\circ}\right)$. According to classical fault mechanics (i.e., faults in an elastic crust obeying Coulomb friction) these structures should not exist in extensional environments characterized by an Andersonian stress field (vertical maximum principal stress; Anderson [1951]), and fault static friction within the Byerlee's 1978 range $\left(0.6<\mu_{\mathrm{s}}<0.85\right.$; Byerlee [1978]). Contrary to this theoretical expectation, many field-based studies [Lister and Davis 1989, Axen 1999, Collettini and Holdsworth 2004] and the interpretation of seismic reflection profiles [e.g. Floyd et al. 2001] indicate that the LANFs can be tectonically active and generate earthquakes [Abers 1991, Wernicke 1995, Rigo et al. 1996, Abers et al. 1997, Axen 1999, Chiaraluce et al. 2007].

An additional motivation for building a NFO in this sector of the Apennines is the presence of deep fluid circulation, which makes the ATF an ideal site for studying the relationship between fluids, seismicity patterns and faulting. Several authors have investigated the seismicity pattern characterising the main seismic sequences occurred in this sector of the Apennines, and one of the main outcomes is that the prolonged aftershocks sequences can be explained in terms of subsequent earthquake failures promoted by fluid flow [Miller at al. 2004, Antonioli et al. 2005, Chiarabba et al. 2009]. The existence of fluid diffusion processes is 
supported by the evidence that, within two deep boreholes drilled in the study area and located in the ATF footwall (Pieve Santo Stefano and San Donato; Figure $1 \mathrm{~B})$, fluid overpressure $\left(\mathrm{CO}_{2}\right)$ at about $85 \%$ of lithostatic load has been encountered. In addition, the isotopic signature of a large number of local springs, indicates that the whole area is interested by an extremely large flux of $\mathrm{CO}_{2}$ from a deep source [Chiodini et al. 2004]. The overpressurization from below of the crustal geological structures of the area, fed by mantle derived $\mathrm{CO}_{2}$, is proposed as one of the primary triggering mechanisms of Apennine earthquakes [Chiodini et al. 2004].

For all these scientific objectives, we decided to deploy a multidisciplinary high- resolution observing system with the perspective of building a permanent research infrastructure: the TABOO Near Fault Observatory. This will represent a novel research framework to tackling the challenge of bridging the gap between natural processes observed in the fields (through seismological, geological and geodetic observations) and those observed in laboratory experiments on rock samples from exhumed faults. This is an added value in term of scientific perspective. These investigations will also contribute to better understand the seismogenic potential of the ATF, therefore contributing to the comprehension of seismic hazard in the study area. Last but not least, the NFO will provide the opportunity to implement and design the evolution of monitoring infrastructures and processing tools to build new services for ground-breaking researches.

\section{Seismotectonic setting of the area}

The study area is located at the Tuscany-UmbriaMarche regions boundary within the northern Apennines (Figure 1), a NE-verging thrust-fold belt undergoing NE-trending extension at a rate of about $3 \mathrm{~mm} / \mathrm{yr}$
[Serpelloni et al. 2005, D’Agostino et al. 2009]. The extension is concentrated in the inner zone of the chain where the strongest historical (MCS intensity $\leq \mathrm{X}$ ) and instrumental $(5.0<\mathrm{M}<6.0)$ earthquakes are located (Figure 1A). The seismicity does not follow the arc shape structures inherited from the previous compressional tectonic phase but clusters along an about 20-30 $\mathrm{km}$ wide longitudinal zone [Chiaraluce et al. 2004, Chiarabba et al. 2005].

Three main earthquakes hit the area in past 20 years (location and focal mechanisms in Figure 1A). The southernmost is the 1997 Colfiorito $\mathrm{M}_{\mathrm{W}} 6.0$ earthquake with its sequence of moderate-magnitude events. Going north we find the 1998 Gualdo Tadino $\mathrm{M}_{\mathrm{w}} 5.1$ and the 1984 Gubbio $M_{w} 5.1$ events, respectively. All these earthquakes activated SW-dipping normal fault systems, thus antithetic to the ATF. The comparison of the 1984's aftershocks distribution with background seismic activity of the area clearly shows how the Gubbio sequence is completely located in the hanging wall of the ATF and does not crosscut the major fault [Chiaraluce et al. 2007]. This observation suggests that the ATF may contribute to constrain at depth the size of the synthetic and antithetic seismogenic faults confining their related seismicity.

In Figure 1A we show the earthquakes (grey points) distribution for the 15 years before (1995-2009) the deployment of the TABOO stations: 9273 events with a completeness magnitude of 1.2 (see histogram in the inset). This is the seismicity recorded and located by the INGV national seismic network (available at: http:/ / iside.rm.ingv.it/iside/standard/index.jsp) that in this area was able to generate a completeness in the catalogue below the mean value of $\mathrm{M}_{\mathrm{L}}=1.7$ computed for the whole Italian territory [Amato and Mele 2008]. Seismic activity is generally spread over the whole study

\begin{tabular}{|c|c|c|c|c|c|c|c|c|c|c|c|}
\hline Year & Mo & Da & Epic.area & RtM & Nip & $\operatorname{Imax}$ & LatM & LonM & Io & Mwdef & DMwdef \\
\hline 1352 & 12 & 25 & Monterchi & Castelli et al. 1996 & 7 & 9 & 43.469 & 12.127 & 9 & 6.44 & 0.54 \\
\hline 1781 & 06 & 03 & Cagliese & Monachesi 1987 & 157 & 10 & 43.597 & 12.512 & 10 & 6.42 & 0.13 \\
\hline 1751 & 07 & 27 & Umbria-Marche Apennines & Guidoboni et al. 2007 & 68 & 10 & 43.225 & 12.739 & 10 & 6.25 & 0.22 \\
\hline 1389 & 10 & 18 & Bocca Serriola & Castelli et al. 1996 & 9 & 9 & 43.527 & 12.299 & 9 & 5.99 & 0.34 \\
\hline 1747 & 04 & 17 & Nocera Umbra & Castelli 2003 & 64 & 9 & 43.204 & 12.769 & 9 & 5.94 & 0.26 \\
\hline 1917 & 04 & 26 & Val Tiberina & Guidoboni et al. 2007 & 134 & $9-10$ & 43.467 & 12.129 & $9-10$ & 5.89 & 0.11 \\
\hline 1789 & 09 & 30 & Val Tiberina & Castelli 2002 & 73 & 9 & 43.510 & 12.217 & 9 & 5.84 & 0.24 \\
\hline 1458 & 04 & 26 & Val Tiberina & Guidoboni et al. 2007 & 5 & $8-9$ & 43.463 & 12.236 & $8-9$ & 5.78 & 0.34 \\
\hline
\end{tabular}

Table 1. Epicentral parameters of the largest historical earthquakes occurred in the study area (from Rovida et al. [2011], and reference therein). The acronyms stand for: Year for the year of the earthquake origin time; $M o$ is the month of the origin time and $D a$ is the day. Epic.Area is the name of the epicentral area; RtM is the reference of the specific macroseismic study; Nip is the number of the intensity points available for the event; Imax is the maximum intensity value; LatM is the epicentral latitude (macroseismic determination); LongM is the epicentral latitude (macroseismic determination); Io is the intensity; Mwdef is the default moment magnitude and Dmwdef is the associated error. 


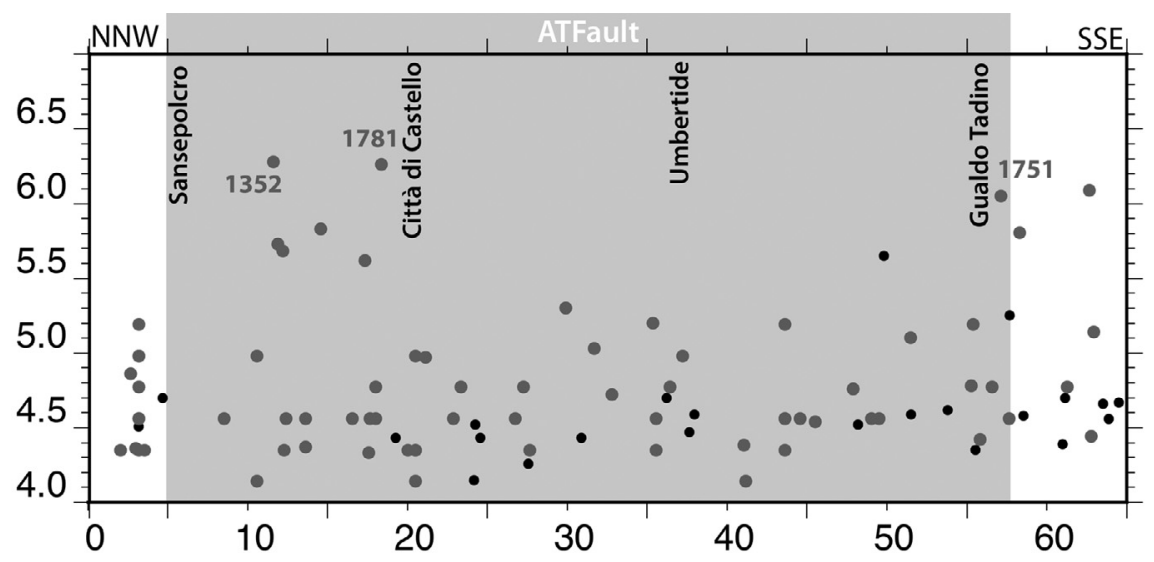

Figure 2. Longitudinal cross section reporting the position of the largest historical (grey points) and instrumental (black points) earthquakes along the strike of the ATF plane. The dates refer to the main historical events. The used catalogues are the same as in Figure 1A. See crosssection trace in Figure 1B.

area. We observe a sort of clustering just along a NWtrending sector placed in between the Gubbio and Città di Castello basins. Regarding the historical earthquakes of the area (red squares in Figure 1A), the CPTI11 catalogue [Rovida et al. 2011] reports several events with $\mathrm{M}_{\mathrm{w}} \geq 5.5$ (see Table 1) that occurred in the 1000-1917 time-window. Three of these earthquakes (Monterchi, 1352; Umbria-Marche Apennines, 1751; Cagliese, 1781) had $\mathrm{M}_{\mathrm{W}}>6$.

The whole picture related to the historical seismicity seems to be coherent with the datum that the major instrumental seismic activity is observed along the northernmost basins, as well as the higher sedimentary rate that has been attributed to the San Sepolcro one (Pucci and Mirabella personal communication). Most of the historical earthquakes occurred in fact on the northern edge of the studied area, from the hills of Monterchi-Citerna (between San Sepolcro and Città di Castello) to the Tiber Valley and nearby foothills to the Umbria-Marche Apennines (near Cagli); then the other earthquakes are located in the southeast corner of the area (near Gualdo Tadino). We remind here that the epicentral parameters of the largest events listed in Table 1 (e.g. 1352, 1751 and 1781) are derived from high quality studies based on extensive historical research. The low number of intensity data points available for the earthquakes occurred before the 18th century (less than ten to each earthquake, against several dozens to over a hundred and fifty data points available for the 18th and 19th century earthquakes) depends on specific historical circumstances. It is well known that the absolute availability of historical sources varies greatly depending on the period and area under study. At the same time we cannot exclude that further research could lead to an improvement in knowledge. For example some new data on medieval frescoes (see Castelli [2002]) contributed to better characterize the effects of the 1352 earthquake.
In Figure 2 we show a cross section drawn along the strike of the fault system (see section trace in Figure $1 \mathrm{~B})$, including the largest historical and the instrumental earthquakes. This comb like picture better highlights the primary remark that no large earthquakes occurred in the central portion of the ATF. Moreover, based on the size of the fault and considering Wells and Coppersmith [1994] relationship between magnitude and rupture length, we define that the average size of an event activating the entire ATF should be around M 7 . This means that the historical records do not contemplate the occurrence of such an event at least in the past 1000 years. The possible explanation for this are: a) the ATF quake has recurrence time larger than 1000 years; b) the fault is not storing/releasing stress, or c) the ATF is sliding aseismically (creeping). TABOO will help us to understand which is the most likely explanation.

\section{The research infrastructure}

We show in Figure 1B the actual configuration of the permanent seismic and geodetic stations installed in the study area. This configuration is essentially stable from April 2010. All the instruments are currently integrated into the INGV National Seismic (RSNC) and Geodetic (RING) networks. The data are real-time transmitted to the INGV acquisition systems providing the data infrastructures for continuous data archiving in standard formats and guaranteeing access to data for scientific purposes. The seismological data are available at the Italian Seismological Instrumental and Parametric Databases (ISIDE) portal (http:/ / iside.rm.ingv.it), while considering of the relatively low strain rate characterizing the study area (around 50 nanostrain/year; D’Agostino et al. [2009]), the GPS network is still relatively too young (on average less than 3 years) to produce stable data. In Figure 3 we show and example of a standard TABOO site where seismic and geodetic sensors are co-located. 


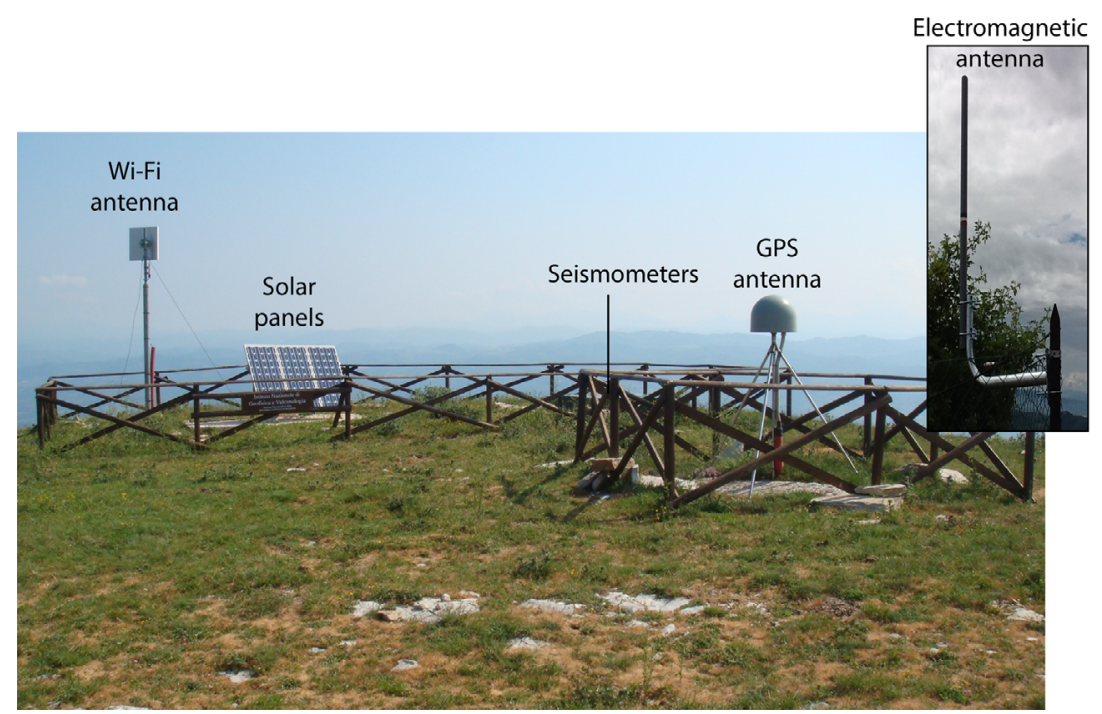

Figure 3. A standard installation of the TABOO network (station ATTE). All of the instruments (GPS and broad-band seismometer) send real time data through a Wi-Fi system based on dedicated radio links [Monachesi and Cattaneo 2010]. In the inset we show a picture of our standard electromagnetic antenna.

Regarding the seismological network, we benefit from a European project named GLASS (Integrated laboratories to investigate the mechanics of aseismic vs. seismic faulting), an ERC (European Research Council) Starting Grant (http: / /www.roma1.ingv.it/ laboratori/laboratorio-hp-ht/glass-project) hosted by INGV, to implement the NFO by drilling and instrumenting a series of three shallow boreholes [Collettini and Chiaraluce 2013]. The small box in Figure 1B indicates the boreholes location area, which is zoomed in Figure 4. We selected this area to deploy the array around a deep $(5.6 \mathrm{~km})$ existing borehole (Mt. Civitello) drilled in the eighties by Italian National organization for Hydrocarbons (ENI), in order to have data available from the past drilling experience to constrain the local one-dimensional (1D) velocity model for $\mathrm{V}_{\mathrm{P}}$ [Chiaraluce et al. 2014]. The three boreholes have a depth of $182 \mathrm{~m}$ (BAT1), $204 \mathrm{~m}$ (BAT2) and $250 \mathrm{~m}$ (BAT3), respectively. Dealing with microseismic activity we decided to instrument the boreholes with 3-component short period seismometers $(2 \mathrm{~Hz})$ sampling the signal at 500 samples per seconds. The sensors are passive to avoid power within the hole. Each borehole has one sensor at the surface and at the bottom depth, while the deepest one (BAT3) has a vertical array with a sensor every $100 \mathrm{~m}(0,50,150$ and $250 \mathrm{~m})$.

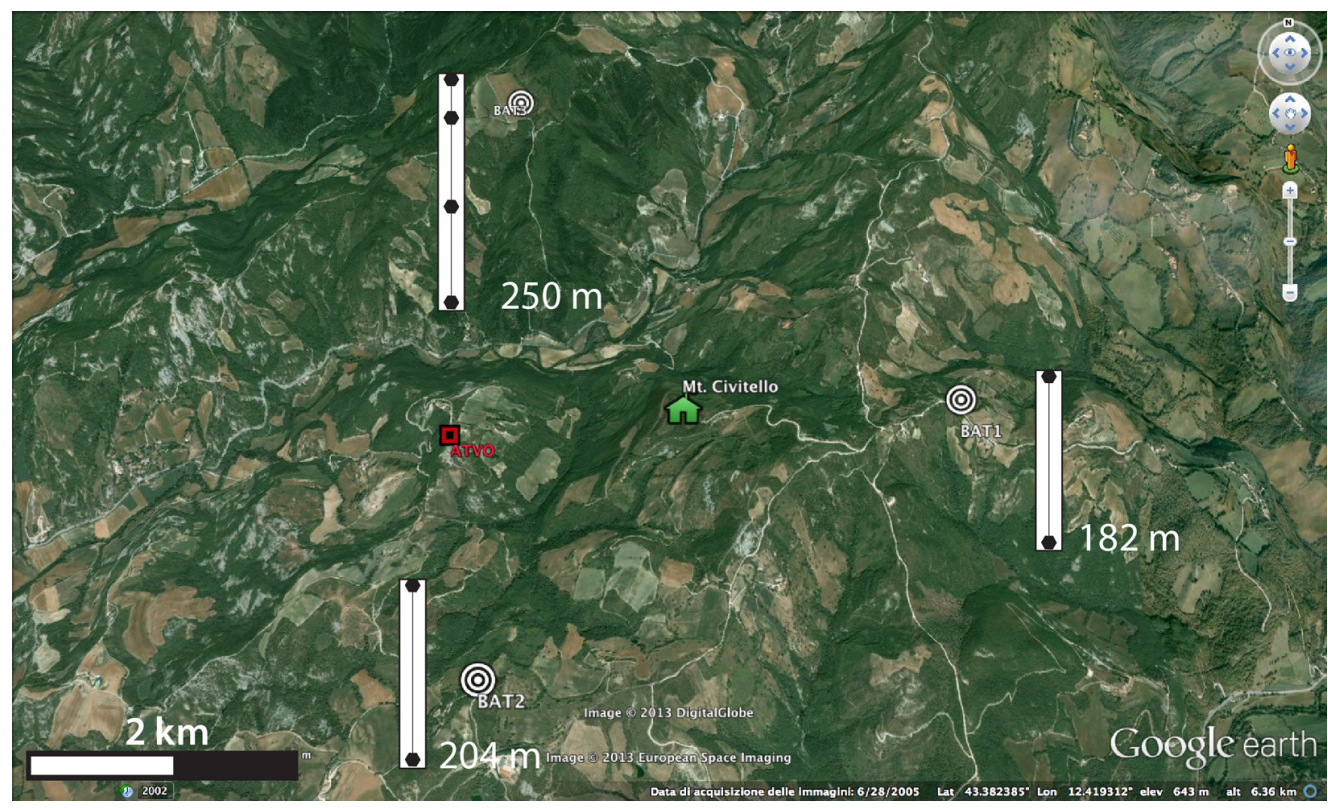

Figure 4. Zoom of the box reported in Figure 1B of the area where the three shallow boreholes instrumented with short period seismometers are located. The green house is the location of the $5.6 \mathrm{~km}$ deep borehole (named Mt. Civitello) while the red square is the location of the seismic and geodetic station ATVO (Monte Valentino). Each (white) column represents the boreholes length (relative scale) with the installed seismometers (black polygons). 

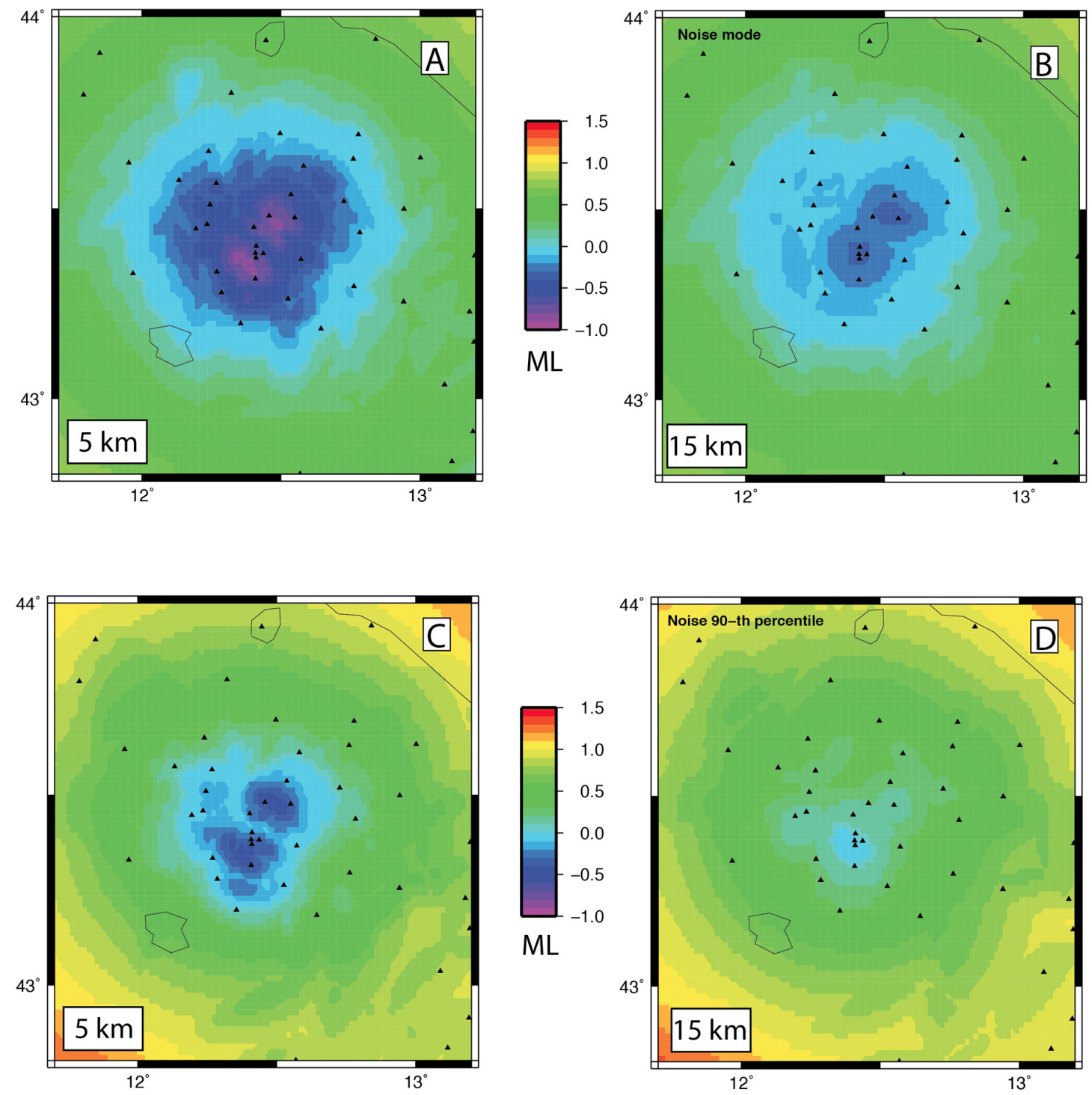

Figure 5. Maps describing the detection capability of the seismic network evaluated by means of an empirical procedure. 5A and 5B show the results obtained using the modal noise estimate at 5 and $15 \mathrm{~km}$ of depth, respectively. 5C and 5D present the worst-case scenario by using the 90th percentile noise estimate always at 5 and $15 \mathrm{~km}$ of depth, respectively. See text for explanation.

We have evaluated the detection capabilities of the whole seismic network by means of a fully empirical procedure. First of all, the background noise of each station was characterized, in terms of Probability Density Functions, by means of the PQLX software [McNamara and Boaz 2010]. In particular, the modal value and the 90th percentile value were taken into account as representative of the stationary noise condition excluding earthquakes and low probability transient noise sources. We computed an empirical magnitude-amplitude-distance relationship for the TABOO area, based on the data recorded by the network in the last 3 years. The analysed amplitude was calculated as the spectral amplitude in a selected frequency band typical of small magnitude events (usually 2-15 Hz). A 3D mesh of source points was set up in the area, and for each point earthquakes of increasing magnitude were simulated; the expected amplitude at each station was compared with the relevant noise level (median or 90th percentile). The lowest magnitude presenting a ratio between the expected amplitude and the noise level above a selected threshold (Th), at a minimum number (n) of stations, is defined as the detection threshold for that point. We set $T h=6$ and $n=6$, values representing a high possibility of obtaining a well-constrained hypocentral location for the detected event.

Figure 5A and $\mathrm{B}$ shows the results obtained using the modal noise estimate, for a time window of one week at the end of November 2012; this choice should assure a rather conservative estimate: noise levels are in fact strongly linked to weather conditions with wind and rain as the main natural noise sources for the area. The detection maps were computed at two different depth levels: $5 \mathrm{~km}$, representing the mean depth of the most frequent seismicity, and $15 \mathrm{~km}$, representing the deepest expected seismicity in the area (with very few 

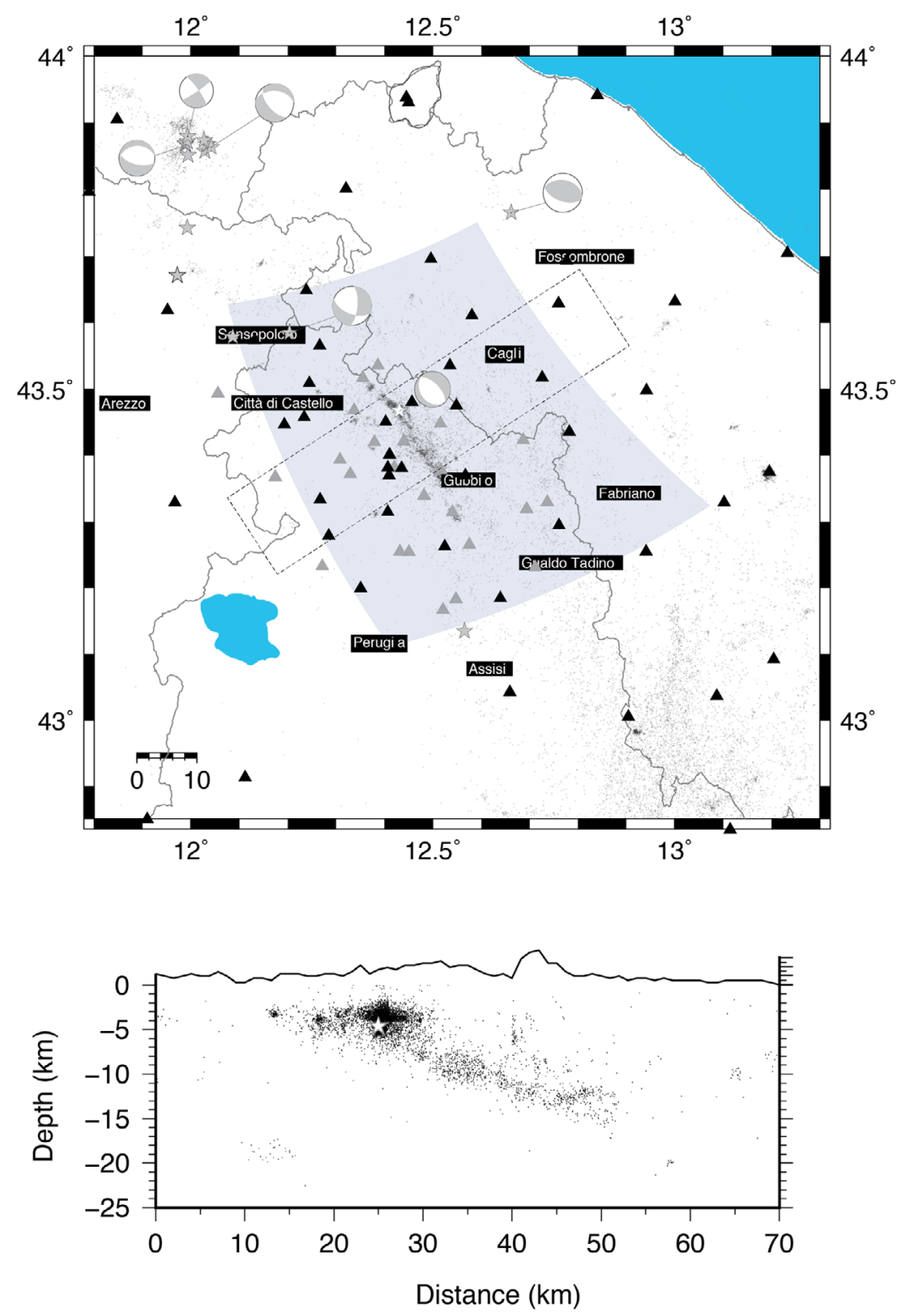

Figure 6. Map of the events recorded during the first three years of monitoring activity (from April 2010 to April 2013). The black and grey triangles represent the permanent and temporary stations, respectively. Grey stars and beach balls are the events with $\mathrm{M}_{\mathrm{L}}>3.0$ and available focal mechanism solutions.

exceptions). Maps A and B in Figure 5 demonstrate that TABOO seismic network provides a very good (i.e. low) detection capability in the sense that we should be able to detect and locate all the events equal and larger than $\mathrm{M}_{\mathrm{L}} 0$ occurring within the whole monitored volume.

Then, in Figure 5C and D, we present the worstcase scenario by using the 90th percentile noise estimate. Clearly the magnitude threshold is increased, nevertheless also for the $15 \mathrm{~km}$ layer a magnitude threshold with negative values characterizes the inner part of the network, and for the surrounding area the network guarantees a detection capability around $\mathrm{M}_{\mathrm{L}}$ 0.5. It is evident the contribution given by the 3 borehole stations producing a relative minimum particularly visible in the map of $15 \mathrm{~km}$ of depth. However, the good detection capability is not only due to the reduced inter-station distance (mean distance around $8 \mathrm{~km}$ ), but also to the rather low noise levels, in the analysed frequency band, characterizing the station sites we selected.

One of the reasons to keep under control the minimum detection capability of the seismic network is to investigate possible breakdown thresholds of the earthquake-size distribution towards very low magnitude earthquakes otherwise following the Gutenberg and Richter law [Gutenberg and Richter 1944].

In Figure 6 we report in map view and cross section the events collected during the first three years of monitoring activity (from April 2010 to April 2013). Grey stars represent the events with magnitude greater than $\mathrm{M}_{\mathrm{L}} 3$ together with the available focal mechanisms derived from the INGV time domain moment tensor (TDMT) catalogue (http:// cnt.rm.ingv.it/tdmt.html). We display also the location of the permanent seismic 
stations (black triangles) together with the temporary ones (grey triangles) that we deployed in the area for one year and a half (2011-2012), to reoccupy the same sites of the 2000-2001 experiment [Piccinini et al. 2003]. In this way, we will be able in the near future to locate together the new and the old set of data. Moreover, a dense station coverage of the area, even if temporary, allows the collection of data to compute a 3D tomographic model better sampling the volume parametrized by smaller grid spacing.

We detected 19,422 events with $\mathrm{M}_{\mathrm{L}} \leq 3.8$. The hypocentral locations are preliminary ones obtained with the 1D velocity model proposed for the area by De Luca et al. [2009]. Once the velocity model will be improved we will relocate the seismicity applying also waveforms similarities techniques to retrieve relative locations improving the relative arrival times.

The seismic activity is mainly concentrated along the San Sepolcro-Gubbio alignment similarly to the general picture given by the seismicity of the previous 15 years (Figure $1 \mathrm{~A}$ ). The main difference is that now the number of events is dramatically greater. In the cross section of Figure 6 drawn perpendicularly to the system we can appreciate how the seismicity deepens at low angle toward the E-NE direction mimicking the ATF geometry. The largest event occurred within the study region is a $\mathrm{M}_{\mathrm{L}} 3.8$ (20100415 01:47 UTC) located nearby the Pietralunga village. A detailed study of this minor sequence highlighted the geometry of the kilometer scale activated high-angle normal fault segment, synthetic to the ATF [Marzorati et al. 2014]. While the aftershocks pattern and related seismicity migration episodes have been related to fluid discharge processes [Chiaraluce 2012] often observed during larger Apenninic normal faulting sequences (e.g. Colfiorito, 1997; L'Aquila, 2009). All these aspects underline the relevance of studying microseismic activity.

We report in Figure 7 the curve describing the cumulative number of the 2010-2013 events versus time (black line). To better estimate the rate of earthquake production, we declustered the catalogue (using the Reasenberg [1985] approach) by removing the aftershocks sequence following the relatively larger events (grey line in Figure 7). The declustering has been performed by applying the Reasenberg algorithm with the standard parameter setting (see Reasenberg [1985] and Lombardi [2003] for details) within the ZMAP code [Wiemer 2001] on the absolute catalogues that include $M_{L}$ above $M_{C}$. The aftershock population is identified by assuming that any earthquake that occurs within an interaction zone of a prior earthquake is an aftershock and is considered statistically dependent on it. Events thus associated are referred to as belonging to a cluster.

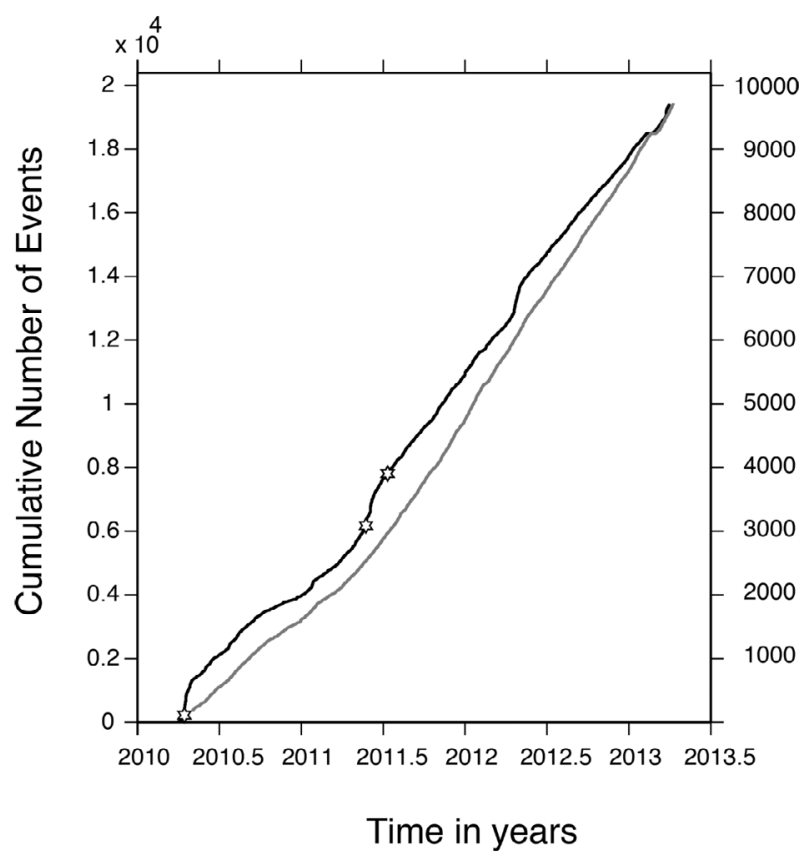

Figure 7. Cumulative number of events versus time for the entire (black line) and declustered (grey line) catalogue. The white stars are the events with $M_{L}$ greater than 3 occurred in the selected area. See text for details.

The interaction zones are dynamically modeled with one spatial and one temporal parameter. We identified a large number of clusters (1462) comprising more than the half of the earthquakes (11,101 events). The declustering removed also the small accelerations in seismic release related to the occurrence of the events with $\mathrm{M}_{\mathrm{L}}>3.0$ (grey stars in Figure 6). We then used the declustered catalogue to compute the number of events per day per squared kilometers $\left(r=\right.$ eqks $/$ day $\left.* \mathrm{~km}^{2}\right)$ occurring in the area around the ATF (shaded area in 1A

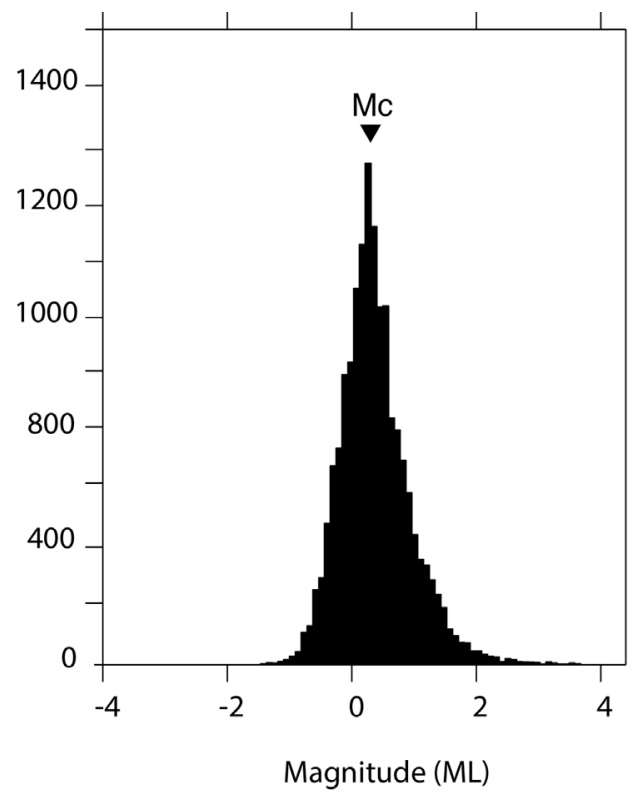

Figure 8. Histogram of the frequency distribution of the events of the selected area, for different classes of magnitude. $\mathrm{M}_{\mathrm{C}}$ is the completeness magnitude of the catalogue. 
and 6). We computed $r$ by using only the events in the catalogue with magnitude larger than completeness magnitude $\left(M_{C} 0.3\right)$ with the intention to minimize the distortion effects when comparing different catalogues retrieved by different seismic networks. We end up with a seismic rate $r=23.36 \mathrm{e}-04$, a value larger that the one $(r=7.30 \mathrm{e}-04)$ obtained by Chiaraluce et al. [2009] for the same area with data of a temporary experiment performed in 2000-2001, having a $\mathrm{M}_{C}=0.6$. Thus the difference can possibly be explained with the difference in $\mathrm{M}_{\mathrm{C}}$ between the two catalogues. The value of $\mathrm{M}_{\mathrm{C}} 0.3$ we obtained (Figure 8) by plotting the frequency distribution of the events for different classes of magnitude is in very good agreement with the map of Figure 5 showing the detection capability of the network.

Physical parameters of the Earth's crust change before some shallow earthquakes as a response to the earthquake preparatory process [Scholz et al. 1973]. Then, to increase the variety of monitored signals we recently implemented the geophysical network by installing a set of proprietary electromagnetic and geochemical sensors co-located with the seismic and geodetic sensors at four common stations.

The geochemical sensor consists of a Radon detector prototype. The measurement is based on the de- tection of the alpha decay typical of the decay process of Radon 222 that is part of the Uranium 238 decay chain. Radon entering the scintillation cell decays with a lifetime of 3.8 days in ${ }^{218} \mathrm{Po},{ }^{214} \mathrm{Po},{ }^{214} \mathrm{Bi}$ and ${ }^{214} \mathrm{~Pb}$. Alpha particles emitted by ${ }^{218} \mathrm{Po}$ and ${ }^{214} \mathrm{Po}$ interact with zinc sulphide distributed on the detector internal side producing photons. A photocathode, the input of a photomultiplier converts emitted photons in electrons that are multiplied by the diodes in the photomultiplier raising in this way a current signal and then a voltage impulse through a resistor. The number of counts during the acquisition time is proportional to the radon concentration. The detector we have constructed is based on an active monitor powered by a $12 \mathrm{~V}$ battery charged by a specific power supply connected to the $220 \mathrm{~V}$ network or to a solar panel. Radon diffuses in a 0.51 scintillation cell through some holes on a flanged enclosure: between the enclosure and the cell there is some black filtering material in order mainly to prevent other radon short living isotopes from entering the cell and bias the measure (diffusion barrier). The sample frequency of radon concentration is $1.3910^{-4} \mathrm{~Hz}(12$ samples in 24 hours). In order to get better insight on the origin of the detected transient signals we installed also a local temperature sensor while other sensible me-
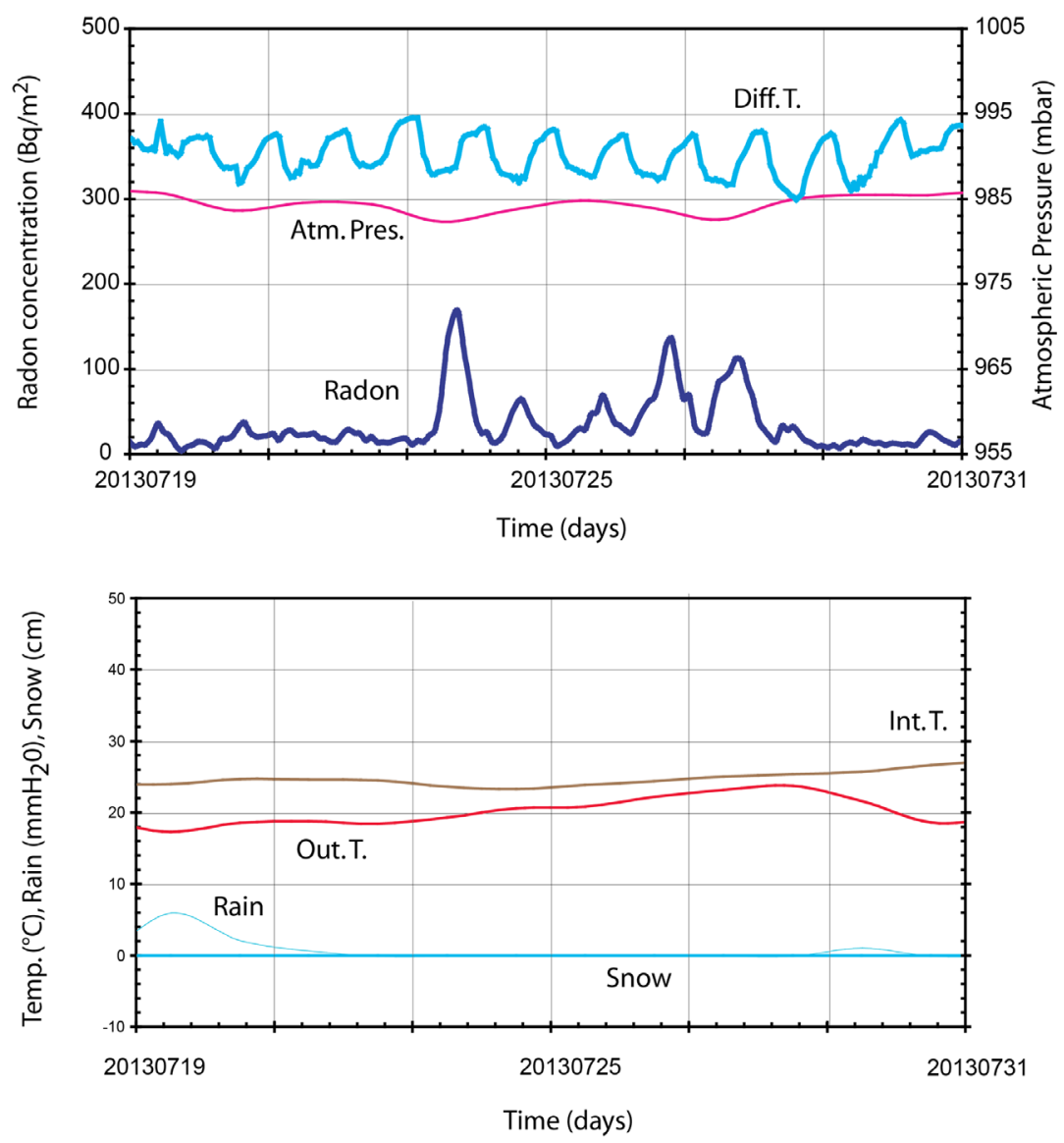

Figure 9. Twelve days of data showing radon concentration and internal temperature measured at MURB station. We report also the main meteorological parameters (e.g. temperature, rain, snow). 
teorological parameters are estimated using available information from public meteorological stations. In Figure 9 we show a time series for few weeks of data collected by MURB station where we can observe that Radon variations are not modulated by meteorological factors. Data from these stations are not yet transmitted to the acquisition centre and this is the succeeding implementation we are working on, to be able to compare the observed behaviour together with all the other monitored parameters.

The electromagnetic active antenna (see inset in Figure 3) is a vertical pipe of the length of one meter. The receiver of very low frequency (VLF) field works on the electric field component in the band that goes from $20 \mathrm{~Hz}$ to $20 \mathrm{kHz}$ with a uniform response in the range between 1 and $13 \mathrm{kHz}$ and the sensitivity of $1 \mu \mathrm{V}$. The monitoring is done in a continuous way to the sampling frequency of $44,100 \mathrm{~Hz}$. The extension of the band corresponds exactly to that of the acoustic frequencies and the recorded electrical signal will be analyzed performing acoustic spectrograms and sonograms that will be compared with the occurrence of the other transients.

We are now also in the process of installing a series of geodetic corner reflectors (homemade at INGV). Generally space geodesy information by means of SAR interferometry (InSAR) will be integrated with ground measurement techniques (such as leveling, GPS). Through an ESA Category-1 project (Exploring the deformation pattern of the upper Tiber Valley natural laboratory) a series of ERS \& ENVISAT SAR images, on ascending and descending orbit, covering a time window between 1992-2010 have been collected and SBAS/IPTA processing are on-going. In addition a network of SAR Passive Corner Reflectors (CRs) will be deployed in the proximity of GPS monuments in order to calibrate SAR velocity map. CRs are designed for the $\mathrm{X}$ band SAR of COSMO-SkyMed. The signals will be then processed for gaining higher resolution products moving for example from $80-100 \mathrm{~m}$ per pixel to $20-30 \mathrm{~m}$ per pixel.

\section{Discussions and conclusion}

With TABOO we intend to permanently monitor at high resolution a relatively small and actively deforming area by means of state of the art geophysical networks comprising multidisciplinary instruments. We believe that only high-resolution data coming from different disciplines can help us in obtaining a comprehensive picture to comprehend tectonic evolution and fault zone processes.

We have still much to learn about the mechanics of faulting and the complex and possibly inherently scale-dependent processes governing fast and slow de- formation processes. Numerous fundamental questions remain unanswered, such as: How did the LANF form and evolve? How do the frictional and rheological properties of fault zones vary in space and time? How do aseismic and seismic slip interact in time and space characterizing the state of stress of active faults? How the stress field is oriented within the upper crust?

We have summarised in the cartoon illustrated in Figure 10 a range of possible deformation behaviours related to misoriented faults (such as the ATF), which will likely be identified and corroborated by the new high-resolution data that we are going to acquire with TABOO. We consider a LANF with fluids (e.g. $\mathrm{CO}_{2}$ ) overpressure trapped in the footwall block. Earthquakes can nucleate within or outside the fault core (Figure $10 \mathrm{~A}$ and $\mathrm{B}$, respectively), possessing different structure and rheological properties. In the first case the fault core has brittle rheology with cataclastic textures and friction coefficient in the Byerlee range (0.6-0.8; Byerlee [1978]). In this case earthquakes may rupture shallow-dipping planes generating moderate to large events. The rupture can initiate on a small (velocity weakening) fault portion where tensile fluid overpressure cannot be sustained [Sibson 1990] and then propagate along the fault plane. In the second case

A)



B)

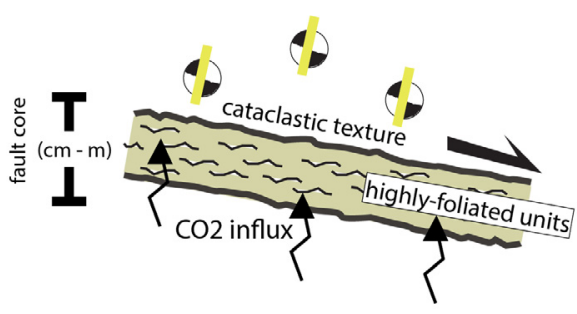

C)

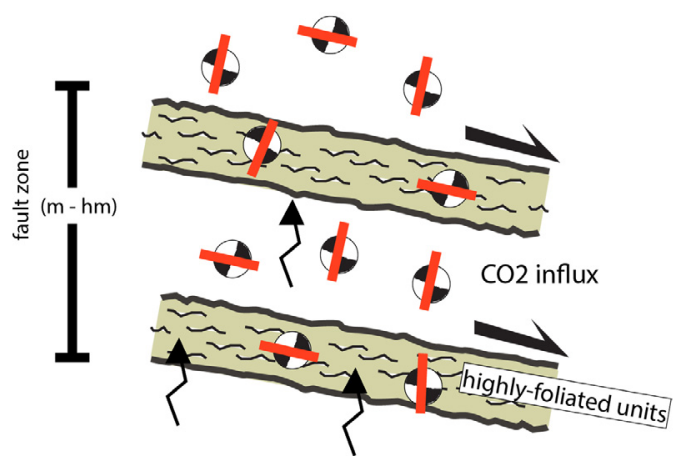

Figure 10. Cartoon showing a schematic sketch of three possible mechanical models explaining the seismic activity and kinematic related to stick slip (earthquakes) and stable sliding (creeping) events occurring within and outside the fault core of a shallow dipping plane. The arrows represent the fluid $\left(\mathrm{CO}_{2}\right)$ fluxes. See test for explanation. 
earthquakes are located right above the fault core (plane) and they rupture the high angle plane as brittle response of the fault hanging-wall to strain localization and ductile deformation (creeping) occurring on the LANF plane. In this case the LANF fault core may be constituted by highly foliated fault rocks such as foliated phyllosilicate-rich fabrics and associated weakening effects due to fluid-rock interaction (e.g. Zuccale fault core; Collettini et al. [2009]). The last scenario (Figure $10 \mathrm{C}$ ) includes multiple discrete fault planes and the slip distributed within a wide fault zone possessing different rheological properties. Microseismic events can occur within the fault zone in velocity weakening patches loaded by many factors like: tectonic stress, stress redistribution caused by aseismic slip on adjacent volumes, coseismic slip of nearby earthquakes, fluid pressure fluctuation and/or pore pressure relaxation. Most of the LANF should slip a-seismically or creep because embedded in velocity strengthening materials. While the microseismic events occurring in the volume may rupture fault planes with different geometries depending on the orientation of the local stress field. Due to the poor knowledge we have on the dynamic rupture propagation we then cannot exclude that a rupture nucleating on a minor well oriented asperity may evolve in a large rupture (e.g. seismic event). We remind here that all these scenarios do not explain the origin of such shallow faults mainly if we suppose that they did not rotate with time [Smith et al. 2011].

With TABOO we want also to understand the seismogenic potential of the ATF and therefore contribute to the seismic hazard assessment of the area. The collected information on the geometry and physical properties of the fault will be useful to elaborate ground shacking scenarios adopting diverse slip distributions and rupture directivity models.

Another important aspect regards the study of the physics of faulting and earthquake preparatory phase and we want to approach these issues investigating the occurrence of transients signals that we define here as the occurrence of space-time variations of elastic properties of the rocks and/or short lived and impermanent signals occurring in the solid crust, spring waters, atmosphere and so on. The ambitious challenge is the observation at small scale of changes in the physical parameters describing the crust during the earthquake preparatory process (e.g. precursory phenomena).

One of the most famous experiments worldwide supporting long-term earthquake research projects to better understand the earthquake process and to provide a scientific basis for earthquake prediction is the Parkfield (California, US) earthquake experiment, a section of the San Andreas fault [Bakun and Lindh 1985].
The geophysical instruments operated at Parkfield by the Geological Survey from 1985, have been designed to monitor tectonic processes leading up to one expected earthquake in the following few years and to record the strong shaking and crustal deformation that will result from it. To this end a heterogeneous configuration of instruments has been deployed to recover seismic, deformation, electromagnetic and fluid related signals. After 30 years of investigations devoted to such ambitious objectives, numerous scientific advances have been gained along the way. This is the area where the high-quality observation derived from the dense seismic network together with the implementation of innovative earthquakes location algorithms [Waldhauser and Ellsworth 2000] allowed an extremely highresolution image of the fault structure [Schaff and Waldhauser 2005]. Looking at these earthquakes nucleating on the San Andreas fault at Parkfield, some of them have been observed to occur as repeating ruptures of discrete patches on the fault surface (repeating earthquakes; Cole and Ellsworth [1995]) and along concentrated streaks on creeping fault sections, northwest of Parkfield [Rubin et al. 1999]. Important improvements have been achieved also concerning fault-zoned fluids and how variations in fluid pressure may affect the timing of earthquakes [Miller et al. 1996]. Lastly, the $\mathrm{M}_{\mathrm{W}} 6.02004$ earthquake that occurred at Parkfield is probably the best-recorded event ever. Following Bakun et al. [2005], the lack of obvious precursors demonstrates that reliable short-term earthquake prediction still is not yet achievable. At the same time Parkfield still remains the major battleground over earthquake prediction and between the concepts of repeatability and variability of earthquakes.

All these major topics largely justify the need for modern multisensory networks implementations and the work we are carrying on to produce high-resolution observations that can be sustained in the long term.

We need to generate a high-resolution earthquakes catalogue to analyse the seismicity pattern (e.g. b-value and rate of production) characterising the events related to the ATF geometry (misoriented) in respect to the one characterising the high angle faults (well oriented). We need to investigate the frequency content and the source parameters of these two groups of events to evaluate if there are systematic differences underlying different mechanical properties. We need to analyse the kinematic of the events studying the focal mechanism solutions to investigate if there is re-orientation of the stress field approaching the ATF plane. Focal mechanism solutions based on the availability of detailed 3-dimensional velocity models at the hundreds of meters scale will be computed through waveforms modelling also for 
smaller events $(M>3.0)$. Velocity models together with the known principal discontinuities (e.g. ATF plane) will be used as starting models for tomographic studies.

Additional insights will be provided by the availability of the dense GPS network. The deformation velocity gradient we are starting to observe through the ATF system [Vadacca et al. 2014] will be used to constrain the interseismic deformation by 2D-3D finite element modelling. This implies the investigation of the effects of different locking depths for the ATF, the role of synthetic and antithetic segments and the effects of the lithology. Subsequently through a block modelling approach we can measure the fault coupling. The imaging of the ATF deep structure obtained from seismic profiles will allow us the modelling of the ATF plane as a complex rough surface to understand where the stress accumulations are located and the interseismic coupling changes. The preliminary results obtained show for the first time that the observed extension is mainly accommodated by interseismic deformation on both the ATF and antithetic faults, highlighting the important role of this LANF inside an active tectonic contest [Vadacca et al. 2014].

Finally, it is important to perform the majority of the analysis with automatic procedures. We already experienced automatic procedures for generating highresolution catalogues of aftershocks sequence (e.g. L'Aquila 2009) reaching a completeness magnitude of $\mathrm{M}_{\mathrm{L}}=0.6$ [Valoroso et al. 2013, and reference therein]. This means having the availability of tens of thousands of earthquakes including repeaters and allowing the researchers to concentrate on the observational aspects.

To this regard we are working on the possibility of transmitting all kind of data to the acquisition centre to be able to visualize the time series all together. In this way we will be able to make inferences basing on multidisciplinary data possibly in quasi-real time. This is our meaning of road to integration to gain advancement on fundamental aspects related to the physics of faulting. In doing this we hope to form a new generation of scientists able to properly integrate data coming from different disciplines.

Acknowledgements. We thank the Associated Editor Christoph Grützner and two anonymous reviewers for their fruitful comments and revision. We acknowledge: M. Frapiccini, V. Lauciani, A. Mandiello, S. Mazza and S. Pintore for their support on data interpretation and storage, and D. Bailo and B. Angioni for their sustenance on TABOO web site construction. We thank T. Braun, L. Mondiali, M. Moretti for their help on the field during the site identification, station construction and temporary experiments. We thank Regione Marche, and in particular M. Ferretti, for the fundamental contribution in the realization of the data transmission infrastructure. We acknowledge the former Directors of the National Earthquake Centre and Seismology and Tectonophysics Department of the INGV, G. Selvaggi and A. Piersanti respectively, for providing us the full support of the INGV infrastructure. We thank N.P. Agostinetti, L. Anderlini, P. Augliera, E. Casarotti, L. Chia-rabba, N. D’Agostino, E. D’Anastasio, P. De Gori, A. Lombardi, F.P. Lucente, L. Margheriti, G. Saccorotti, L. Scognamiglio, E. Serpelloni, M. Spada, E. Tinti, L. Vadacca, for stimulating discussions. We acknowledge the following projects for sustaining TABOO activity and implementation: AIRPLANE (MIUR), PREMIALI (MIUR), DPC, EPOS (ESFRI-EU), GLASS (ERC-EU), NERA (FP7-EU). L. Chiaraluce was supported by EPOS No. 262229 project. L. Valoroso was supported by the ERC St. G. No. 259256 GLASS project. R. Di Stefano and D. Latorre were supported by the Premiali-2012 project funded by MIUR.

\section{References}

Abers, G.A. (1991). Possible seismogenic shallow-dipping normal faults in the Woodlark-D'Entrecasteaux extensional province, Papua New Guinea, Geology, 19, 1205-1208.

Abers, G.A., C.Z. Mutter and J. Fang (1997). Shallow dips of normal faults during rapid extension: earthquakes in the Woodlark-D'Entrecasteaux rift system, Papua New Guinea, J. Geophys. Res., 102, 15301-15317.

Amato, A., and F. Mele (2008). Performance of the INGV National Seismic Network from 1997 to 2007, Annals of Geophysics, 51 (2-3), 417-431.

Anderson, E.M. (1951). The Dynamics of Faulting, 2nd edition, Oliver and Boyd, Edinburgh, 206.

Anelli, L., M. Gorza, M. Pieri and M. Riva (1994). Subsurface well data in the northern Apennines, Memorie della Società Geologica Italiana, 48, 461-471.

Antonioli, A., D. Piccinini, L. Chiaraluce and M. Cocco (2005). Fluid flow and seismicity pattern: Evidence from the 1997 Umbria-Marche (central Italy) seismic sequence, Geophys. Res. Lett., 32, L10311; doi: 10.1029/2004GL022256.

Axen, G.J. (1999). Low-angle normal fault earthquakes and triggering, Geophys. Res. Lett., 26, 3693-3696.

Bakun, W.H., and A. Lindh (1985). The Parkfield, California, earthquake prediction experiment, Science, 229 (4714), 619-624.

Bakun, W.H., B. Aagaard, B. Dost, W.L. Ellsworth, J.L. Hardebeck, R.A. Harris, C. Ji, M.J.S. Johnston, J. Langbein, J.J. Lienkaemper, A.J. Michael, J.R. Murray, R.M. Nadeau, P.A. Reasenberg, M.S. Reichle, E.A. Roeloffs, A. Shakal, R. W. Simpson and F. Waldhauser (2005). Implications for prediction and hazard assessment from the 2004 Parkfield earthquake, Nature, 437, 969-974; doi:10.1038/nature04067.

Barchi, M., R. Minelli and G. Pialli (1998). The crop 03 profile: a synthesis of results on deep structures of the northern Apennines, Memorie della Società Geologica Italiana, 52, 383-400.

Boncio, P., F. Brozzetti and G. Lavecchia (2000). Architecture and seismotectonics of a regional low-angle 
normal fault zone in central Italy, Tectonics, 19, 1038-1055.

Brozzetti, F., P. Boncio, G. Lavecchia and B. Pace (2009). Present activity and seismogenic potential of a low angle normal fault system (Città di Castello, Italy): Constraints from surface geology, seismic reflection data and seismicity, Tectonophysics, 463, 3146; doi:10.1016/j.tecto.2008.09.023.

Buck, W. (1993). Effect of lithospheric thickness on the formation of high and low angle normal faults, Geology, 21, 933-936; doi:10.1130/00917613(1993)021.

Byerlee, J.D. (1978). Friction of rocks, Pure Appl. Geophys., 116, 615-629.

Castelli, V., G. Monachesi, A. Moroni and M. Stucchi (1996). I terremoti toscani dall'anno 1000 al 1880: schede sintetiche, GNDT, Rapporto interno, Macerata/Milano, $314 \mathrm{pp}$.

Castelli, V. (2002). Il terremoto del 1789 a Città di Castello: ricostruzione dell'impatto e della distribuzione dei danni a partire da documenti inediti, Ingegneria Sismica, 1, 78-85.

Castelli, V. (2003). Revisione delle conoscenze sui terremoti del 1558 (Valdambra), 1561 (Campania-Basilicata), 1639 (Amatriciano) e 1747 (Nocera Umbra Gualdo Tadino), Rapporto tecnico INGV-MI, Milano, $16 \mathrm{pp}$.

Chiarabba, C., L. Jovane and R. Di Stefano (2005). A new view of Italian seismicity using 20 years of instrumental recordings, Tectonophysics, 395, 251-268.

Chiarabba, C., P. De Gori and E. Boschi (2009). Porepressure migration along a normal-fault system resolved by time repeated seismic tomography, Geology, 37, 67-70.

Chiaraluce, L., A. Amato, M. Cocco, C. Chiarabba, G. Selvaggi, M. Di Bona, D. Piccinini, A. Deschamps, L. Margheriti, F. Courboulex and M. Ripepe (2004). Complex Normal Faulting in the Apennines Thrustand-Fold Belt: The 1997 Seismic Sequence in Central Italy, B. Seismol. Soc. Am., 94 (1), 99-116.

Chiaraluce, L., C. Chiarabba, C. Collettini, D. Piccinini and M. Cocco (2007). Architecture and mechanics of an active low-angle normal fault: Alto Tiberina Fault, northern Apennines, Italy, J. Geophys. Res., 112, B10310; doi:10.1029/2007JB005015.

Chiaraluce, L., L. Valoroso, M. Anselmi, S. Bagh and C. Chiarabba (2009). A decade of passive seismic monitoring experiments with local networks in four Italian regions, Tectonophysics, 476, 85-98; http:// dx. doi.org/10.1016/j.tecto.2009.02.013.

Chiaraluce, L. (2012). Unravelling the complexity of Apenninic extensional fault systems: A review of the 2009 L'Aquila earthquake (Central Apennines, Italy), J. Struct. Geol., 42, 2-18; http:/ / dx.doi.org/10. 1016/j.jsg.2012.06.007.

Chiaraluce, L., C. Collettini, M. Cattaneo and G. Monachesi (2014). The shallow boreholes at the Alto Tiberina Near Fault Observatory (TABOO; northern Apennines of Italy), Scientific Drilling, 2, 1-5; doi:10.5194/sd-2-1-2014.

Chiodini, G., C. Cardellini, A. Amato, E. Boschi, S. Caliro, F. Frondini and G. Ventura (2004). Carbon dioxide Earth degassing and seismogenesis in central and southern Italy, Geophys. Res. Lett., 31, L07615; doi:10.1029/2004GL019480.

Cole, A.T., and W.L. Ellsworth (1995). Earthquake clustering and the long-term evolution of seismicity near Parkfield, California, 1931-1994 (abs.), Seismol. Res. Lett., 66 (2), 28.

Collettini, C., M.R. Barchi, C. Pauselli, C. Federico and G. Pialli (2000). Seismic expression of active extensional faults in northern Umbria (central Italy), J. Geodyn., 29, 309-321; ISSN:0264-3707.

Collettini, C., and R.H. Sibson (2001). Normal faults normal friction?, Geology, 29, 927-930.

Collettini, C., and M.R. Barchi (2002). A low angle normal fault in the Umbria region (central Italy): A mechanical model for the related microseismicity, Tectonophysics, 359, 97-115.

Collettini, C., M.R. Barchi, L. Chiaraluce, F. Mirabella and S. Pucci (2003). The Gubbio fault: can different methods give pictures of the same object?, J. Geodyn., 36 (1-2), 51-66; ISSN:0264-3707.

Collettini, C., and R.E. Holdsworth (2004). Fault zone weakening processes along low-angle normal faults: insights from the Zuccale Fault, Isle of Elba, Italy, J. Geol. Soc. London, 161, 1039-1051.

Collettini, C., C. Viti, S.F.A. Smith and R.E. Holdsworth (2009). The development of interconnected talc networks and weakening of continental low-angle normal faults, Geology, 37, 567-570.

Collettini, C. (2011). The mechanical paradox of low angle normal faults: current understanding and open questions, Tectonophysics, 510, 253-268.

Collettini, C., and L. Chiaraluce (2013). Integrated laboratories to study aseismic and seismic faulting, EOS, 94 (10), 97-104.

D’Agostino, N., S. Mantenuto, E. D’Anastasio, A. Avallone, M. Barchi, C. Collettini, F. Radicioni, A. Stoppini and G. Fastellini (2009). Contemporary crustal extension in the Umbria-Marche Apennines from regional CGPS networks and comparison between geodetic and seismic deformation, Tectonophysics, 476, 3-12.

D’Alema, E., M. Cattaneo, M. Frapiccini, S. Marzorati, G. Monachesi and M. Ferretti (2011). Rete Sismometrica Marchigiana e sua integrazione con la RSN 
e Rete AVT, In: M. Cattaneo and M. Moretti (eds.), Riassunti estesi del $1^{\circ}$ workshop tecnico monitoraggio sismico del territorio nazionale. Stato dell'arte e sviluppo delle reti di monitoraggio, Miscellanea INGV, 10, 19-21; ISSN:2039-6651.

De Luca, G., M. Cattaneo, G. Monachesi and A. Amato (2009). Seismicity in central and northern Apennines integrating the Italian national and regional networks, Tectonophysics, 476, 121-135.

Finocchio, D., S. Barba, S. Santini and A. Megna (2013). Interpreting the interseismic deformation of the Altotiberina Fault (central Italy) through 2D modelling, Annals of Geophysics, 56 (6), S0673; doi:10.44 $01 /$ ag-5806.

Floyd, J.S., J.C. Mutter, A.M. Goodliffe and B. Taylor (2001). Evidence for fault weakness and fluid flow within active low-angle normal fault, Nature, 411, 779-783.

Guidoboni, E., G. Ferrari, D. Mariotti, A. Comastri, G. Tarabusi and G. Valensise (2007). CFTI4Med, Catalogue of Strong Earthquakes in Italy (461 B.C. - 1997) and Mediterranean Area (760 B.C. - 1500), INGVSGA; http: / / storing.ingv.it/cfti4med/.

Gutenberg, R., and C.F. Richter (1944), Frequency of earthquakes in California, B. Seismol. Soc. Am., 34, 185-188.

Hreinsdottir, S., and R.A. Bennett (2009). Active aseismic creep on the Alto Tiberina lowangle normal fault, Italy, Geology, 37, 683-686.

Jackson, J.A.N., and J. White (1989). Normal faulting in the upper continental crust: observations from regions of active extension, J. Struct. Geol., 11, 15-36.

Lister, G.S., and G.A. Davis (1989). The origin of metamorphic core complexes and detachment faults formed during Tertiary continental extension in the northern Colorado River region, USA, J. Struct. Geol., 11, 65-93.

Lombardi, A.M. (2003). The maximum likelihood estimator of $b$-value for mainshocks, B. Seismol. Soc. Am., 93, 2082-2088.

Marzorati, S., M. Massa, M. Cattaneo, G. Monachesi and M. Frapiccini (2014). Very detailed seismic pattern and migration inferred from the April 2010 Pietralunga (northern Italian Apennines) micro earthquake sequence, Tectonophysics, 610, 91-109; http:// dx.doi.org/10.1016/j.tecto.2013.10.014.

McNamara, D.E., and R.I. Boaz (2010). PQLX: A Seismic Data Quality Control System. Description, Applications, and Users Manual, U.S.G.S. Open File Report 2010-1292.

Miller, S.A., A. Nur and D.L. Olgaard (1996). Earthquakes as a coupled shear stress-high pore pressure dynamical system, Geophys. Res. Lett., 23 (2), 197-200.
Miller, S.A., C. Collettini, L. Chiaraluce, M. Cocco, M.R. Barchi and J.P.K. Boris (2004). Aftershocks driven by a high pressure $\mathrm{CO}_{2}$ source at depth, Nature, 427; http:/ / dx.doi.org/10.1038/nature02251.

Mirabella, F., F. Brozzetti, A. Lupattelli and M.R. Barchi (2011). Tectonic evolution of a low angle extensional fault system from restored cross sections in the northern Apennines (Italy), Tectonics, 30, TC6002; doi:10.1029/2011TC002890.

Monachesi, G. (1987). Revisione della sismicità di riferimento per i comuni di Cerreto d'Esi (AN), Esanatoglia (MC), Serra San Quirico (AN), Osservatorio Geofisico Sperimentale, Macerata, Internal report, $240 \mathrm{pp}$.

Monachesi, G., and M. Cattaneo (2010). La dorsale radio Wi-Fi per il monitoraggio multiparametrico in Alta Val Tiberina, Rapporti Tecnici INGV, No. 129.

Monachesi, G., M. Cattaneo, C. Ladina, S. Marzorati, E. D’Alema, M. Frapiccini, S. Carannante, M. Ferretti, M. Sebastianelli, A. Delladio and G. Selvaggi (2013). Esperienze di monitoraggio integrato: il caso della Rete Sismometrica dell'Italia centro orientale e dei suoi servizi, Quaderni di Geofisica, 106, 27 pp.; ISSN:1590-2595.

Pialli, G., M. Barchi and G. Minelli (1998). Results of the CROP03 deep seismic reflection profile, Memorie della Società Geologica Italiana, 52, 657 pp.

Piccinini, D., M. Cattaneo, C. Chiarabba, L. Chiaraluce, M. De Martin, M. Di Bona, M. Moretti, G. Selvaggi, P. Augliera, D. Spallarossa, G. Ferretti, A. Michelini, A. Govoni, P. Di Bartolomeo, M. Romanelli and J. Fabbri (2003). A microseismic study in a low seismicity area of Italy: the Città di Castello 2000-2001 experiment, Annals of Geophysics, 46 (6), 1315-1324.

Reasenberg, C.F. (1985). Second order moment of central California seismicity, 1962-1982, J. Geophys. Res., 90, 5479-5495.

Rigo, A., H. Lyon-Caen, R. Armijo, A. Deschamps, D. Hatzfeld, K. Makropoulos, P. Papadimitriou and I. Kassaras (1996). A microseismic study in the western part of the Gulf of Corinth (Greece): Implications for large-scale normal faulting mechanisms, Geophys. J. Int., 126, 663-688.

Rovida, A., R. Camassi, P. Gasperini and M. Stucchi, eds. (2011). CPTI11, the 2011 version of the Parametric Catalogue of Italian Earthquakes. Milano, Bologna, http: / / emidius.mi.ingv.it/CPTI; doi:10. 6092/INGV.IT-CPTI11.

Rubin, A.M., D. Gillard and J.-L. Got (1999). Streaks of microearthquakes along creeping faults, Nature, 400, 635-641.

Schaff, D.P., and F. Waldhauser (2005). Waveform Cross-Correlation-Based Differential Travel-Time 
Measurements at the Northern California Seismic Network, B. Seismol. Soc. Am., 95, 2446-2461; doi:10. $1785 / 0120040221$.

Scholz, C.H., L.R. Sykes and Y.P.A. Aggarwal (1973). Earthquake predictin: a physical basis, Science, 181, 803.

Serpelloni, E., M. Anzidei, P. Baldi, G. Casula, and A. Galvani (2005). Crustal velocity and strain-rate fields in Italy and surrounding regions: New results from the analysis of permanent and non-permanent GPS networks, Geophys. J. Int., 161 (3), 861-880; doi:10. 1111/j.1365-246X.2005.02618.x.

Sibson, R.H. (1990). Conditions for fault-valve behaviour, In: R.J. Knipe and E.H. Rutter (eds.), Deformation Mechanisms, Rheology and Tectonics, Geological Society London Special Publication, 54, 15-28.

Smith, S.A.F., R.E. Holdsworth and C. Collettini (2011). Interactions between low-angle normal faults and plutonism in the upper crust: Insights from the Island of Elba, Italy, Geological Society of America Bulletin, 123, 329-346.

Trippetta, F., C. Collettini, S. Vinciguerra and P.G. Meredith (2010). Laboratory measurements of the physical properties of Triassic Evaporites from central Italy and correlation with geophysical data, Tectonophysics, 492, 121-132; doi:10.1016/j.tecto. 2010.06.001.

Vadacca, L., L. Anderlini, E. Casarotti, E. Serpelloni, L. Chiaraluce, M. Polcari, M. Albano and S. Stramondo (2014). Active tectonic extension across the Alto Tiberina normal fault system from GPS data modeling and InSAR velocity maps: new perspectives within TABOO Near Fault Observatory, Geophysical Research Abstracts, 16, EGU2014-6325-1, EGU General Assembly.

Valoroso, L., L. Chiaraluce, D. Piccinini, R. Di Stefano, D. Schaff and F. Waldhauser (2013). Radiography of a normal fault system by 64,000 high-precision earthquake locations: The 2009 L'Aquila (central Italy) case study, J. Geophys. Res. Solid Earth, 118; doi:10. $1002 /$ jgrb. 50130 .

Waldhauser, F., and W. L. Ellsworth (2000). A doubledifference earthquake location algorithm: Method and application to the northern Hayward Fault, California, B. Seismol. Soc. Am., 90, 1353-1368.

Wells, D.L., and K.J. Coppersmith (1994). New Empirical Relationships Among Magnitude, Rupture Length, Rupture Width, Rupture Area, And Surface Displacement, B. Seismol. Soc. Am., 84 (4), 974-1002.

Wernicke, B. (1995). Low-angle normal faults and seismicity: A review, J. Geophys. Res., 100, 20159-20174.

Westaway, R., R. Gawthorpe and M. Tozzi (1989). Seismological and field observations of the 1984 Lazio-
Abruzzo earthquakes: implications for the active tectonics of Italy, Geophys. J. Int., 98, 489-514.

Westaway, R., (1999). The mechanical feasibility of lowangle normal faulting, Tectonophysics, 308, 407-443.

Wiemer, S. (2001). A software package to analyze seismicity: ZMAP, Seismol. Res. Lett., 72, 373-382.

\footnotetext{
*Corresponding author: Lauro Chiaraluce, Istituto Nazionale di Geofisica e Vulcanologia, Centro Nazionale Terremoti, Rome, Italy; email: lauro.chiaraluce@ingv.it.

C 2014 by the Istituto Nazionale di Geofisica e Vulcanologia. All rights reserved.
} 